\title{
An Investigation on the Factor Structure of Hindi Version of Oxford Happiness Questionnaire (OHQ) ${ }^{*}$
}

\section{Una investigación sobre la estructura factorial de la versión hindú del Cuestionario Oxford de Felicidad (OHQ)}

\author{
Thiruchelvi Arunachalam ${ }^{\mathrm{a}}$ \\ Anna University, India \\ ORCID: http://orcid.org/0000-0002-3881-315X
}

$\begin{array}{ll}\text { a Correspondence author. } & \text { Email: } \\ \text { tiruchelvi_y@annauniv.edu } & \end{array}$

How to cite: Arunachalam, T. (2018). An Investigation on the Factor Structure of Hindi Version of Oxford Happiness Questionnaire (OHQ). Universitas Psychologica, 18(1), 1-11. https://doi.org/10.11144/Jav eriana.upsy18-1.ifsh

\begin{abstract}
This study examines the factor structure of the Hindi version of the Oxford Happiness Questionnaire (OHQ) (Hills \& Argyle, 2002) in a sample of 1000 Indian university students. OHQ is a widely used in positive psychology research. Exploratory factor analysis (EFA)has resulted in six factors. Another study has been carried to test the results of EFA and other reported models with a sample of 800 students. Confirmatory factor analysis has resulted in the six-factor model showing a better fit against the other tested models. The study results support the multi-dimensional structure of OHQ. The factor structure of OHQ in India has some common factors and many differences when compared to the Euro-American studies.

Keywords
\end{abstract}

Happiness; OHQ; India; University Students; Culture; Factor structure; Model Fit.

\section{RESUMEN}

Este estudio examina la estructura factorial de la versión hindu del Cuestionario Oxford de Felicidad (OHQ) (Hills \& Argyle, 2002) en una muestra de 1000 estudiantes universitarios indios. El OHQ es ampliamente utilizado en la investigación de la psicología positiva. El análisis factorial exploratorio (AFE) ha dado como resultado seis factores. Se realizó otro estudio para evaluar los resultados del AFE y otros modelos informados con una muestra de 800 estudiantes. El análisis factorial confirmatorio resultó en el modelo de seis factores mostrando un mejor ajuste en contraste con los otros modelos probados. Los resultados del estudio apoyan la estructura multidimensional del OHQ. La estructura factorial del $\mathrm{OHQ}$ en India tiene algunos factores comunes y muchas diferencias en comparación con los estudios euroamericanos.

\section{Palabras clave}

felicidad; OHQ; India; estudiantes universitarios; cultura; estructura factorial; ajuste del modelo.

Traditionally, psychologists have paid greater attention to the concept of 'unhappiness' which has many forms like depression, anxiety, stress, and burnout. This has led to 
an imbalance between the number of studies on depression and studies on positive emotions. However, recent research on positive psychology has thrown light on the concept of happiness and studies on happiness are on the rise (Diener, 2000; Argyle, 2001). Happiness and depression are the opposite ends of a bipolar valence dimension (Russell \& Barrett, 1999), because one looks at the positive side while the other looks at the negative part of the emotions.

Lu, Gilmour and Kao (2001) have defined happiness as a two-dimensional process namely the predominance of positive over negative affect and as satisfaction with life as a whole. Diener, Suh, Lucas and Smith (1999) in their seminal work on components of subjective well-being have conceptualized psychological or subjective well-being as a broad construct encompassing four specific and distinct components. These components include: (a) pleasant affect or positive well-being (e.g., joy, elation, happiness, and mental health), (b) unpleasant affect or psychological distress (e.g., guilt, shame, sadness, anxiety, worry, and anger), (c) life satisfaction or a global evaluation of one's life, and (d) domain or situation satisfaction (e.g., family, leisure, and health). In summary, though there are many paradigms of well-being are available, no consensus has yet arrived on the components of well-being as cultural differences need to be addressed (Vaingankar et al., 2012). Hence, not only the term subjective well-being but also the components of subjective well-being are multidimensional (Holder, 2012; Pavot, 2018).

Though there are controversies on the objective and subjective measurement of happiness as well as on the distortions that could happen when subjects are asked to rate their happiness (Veenhoven, 1991), a large number of scales have been developed to measure happiness. Of the various measures, the Oxford Happiness Questionnaire (OHQ) is the most widely used questionnaire in the study of happiness and well-being (Chamorro-Premuzic, Bennett \& Furnham, 2007).

Argyle, Martin and Crossland (1989) developed the Oxford Happiness Inventory (OHI) along the lines of the Beck Depression
Inventory (Beck, Ward, Mendelson, Hock \& Erbaugh, 1961) with 32 items that encompass positive affect, negative affect, and subjective well-being. Each item was presented in four incremental levels with ratings from 0 to 3 . After testing this inventory with graduate students of psychology, they finalized the inventory with 29 items. Hills and Argyle (2002) revised the $\mathrm{OHI}$ and devised the Oxford Happiness Questionnaire (OHQ) with 29 items by adopting six-point Likert scale and reversing about half of the items. They opined that OHQ is an improved scale over the OHI with better psychometric properties.

However, few questions have raised doubts on the factor structure of OHQ. First, the study on 172 undergraduate students has resulted in a seven-factor structure for the $\mathrm{OHI}$ and an eight-factor structure for OHQ (Hills \& Argyle, 2002). While describing the structure adopted for designing OHI, Hills and Argyle (2002) state that they have taken mainly the positive affect, negative affect, subjective well-being and happiness factors into account, but the resultant seven factors have not been discussed vis-a-vis the definition taken. Even for the seven factors retrieved, the items in these factors have not been reported. However, they state that the seven factors are similar to the factors retrieved by the earlier study of Hills and Argyle (1998).

Hills and Argyle (2002) have extracted the eight factors from OHQ, but they could not interpret them clearly. Varimax rotation had resulted in similar items falling in 2 or more factors, and they were not satisfied with the results. Further, the factors of OHQ reported a low correlation with factors of $\mathrm{OHI}$. They argue that the more significant number of factors $(8$ factors) extracted might have been the cause of non-interpretability but attempts to extract fewer factors also could not explain a higher variance, aiding researchers to analyze the factor structure of OHQ. As the factor analysis of OHQ could not result in a clear factor structure, they have suggested that the sum of all the item scores is an overall measure of psychological well-being with high scores indicating higher well-being. When OHI with seven factors could not be 
interpreted, a detailed study on a larger sample may prove to be fruitful in explaining the factor structure of the OHQ. They also state that the primary aim of designing $\mathrm{OHQ}$ and analyzing the psychometric properties is to place the OHQ in the public domain for further examination. Till date, no evidence could be found on the use of the confirmatory factor analysis (CFA) techniques in confirming the factor structure of OHQ.

As OHQ is the widely used questionnaire in positive psychology research, the issue is whether the OHQ can be used as a uni-dimensional or as a multi-dimensional measure. The standard uni-dimensional approach for the quality of life measures would fail mostly as unidimensionality is the strict requirement (Slocum-Gori, Zumbo, Michalos \& Diener, 2009). Also, there is a possibility of differences in the factor structure of OHQ across nations. Differences in the level of happiness among countries are very large as happiness depends on the aspirations of the people to adjust and the standards of life (Veenhoven, 2010; Wang \& Wang, 2016). The characteristics of the nation also play a significant role in explaining the nature and levels of happiness (Diener, Tay \& Oishi, 2013; Oishi \& Gilbert, 2016). Diener, Suh, Lucas and Smith (1999) have shown that the national culture moderates the relation among the components of subjective well-being.

It is possible that happiness takes different forms across cultures. Culture influences the feelings and emotions of a person, and in turn, these emotional experiences may influence her/his level of happiness and perception of happiness. In the West, happiness is conceptualized as more related to intrapersonal or internal evaluation whereas in China happiness is more related to interpersonal or external evaluation ( $\mathrm{Lu} \&$ Shih, 1997). In fact, Kitayama, Markus and Kurokawa (2000) suggest that how we understand, and experience wellbeing varies with the level of individualism and collectivism in a culture (Ahuvia, 2002). Self- esteem is valued more by individualistic culture and more related to life satisfaction but less realistic in collectivistic culture (Diener $\&$ Diener, 2009).

Furthermore, the predictors of life satisfaction differ between individualist and collectivist societies (Oishi, Diener, Lucas \& Suh, 1999) and individualists consider their own satisfaction more frequently than collectivists (Diener et al., 1999). In certain cultures, people do not report feelings of depression, sadness and guilt openly as in Indian culture (Argyle, 2001). There is a huge difference between the American and Asian culture in terms of how people conceive happiness and what determines happiness (Howell, Chong, Howell \& Schwabe, 2012; Uchida \& Ogihara, 2012) and especially the Indian perspective of happiness and the hedonic notion of happiness of the Western nations (Nagar, 2017). These studies have led some researchers to theorize that culture influences well-being (Church, 2000). Hence, countries differ in their happiness levels because of ethnic, cultural, economic, political and religious differences. The focus of cross-cultural perspectives on happiness is essential to eradicate the risk of assuming universal conditions of human well-being. The impact of culture and cultural norms are high on the perceived wellbeing thereby giving room to analyze the factors of happiness (Argyle, 2001; Islam, 2012). Diener, Oishi and Ryan (2013) have opined that both the structure of subjective well-being (SWB) and its components have culture-specific aspects that need to be widely researched.

India is an interesting case for studies on happiness as it is a unique country with cultural traditions unlike anywhere else in the world (Biswas-Diener, Tay \& Diener, 2012). With the rapid economic development and growth in Information Technology (IT) sector, the nation is on the brink of changes. This has led many researchers (Chakraborty et al., 2018; Veenhoven, 2010) trying to understand the happiness of the Indian continent.

Because of the growth of IT sector, the work patterns of Indian workforce have changed. This has led to increased stress and depression levels among Indian professionals. According to the estimates of PPC worldwide, more than $62 \%$ of 
health concern in India in the year 2012 was due to work stress. In a study by Saddichha (2010), it is reported that $19 \%$ of the collegegoing population suffers from depression and anxiety disorders. $72 \%$ of students in India are reported to suffer from stress and its ill-effects. Sixteen thousand students in India committed suicide between 2004 and 2008 because of stress (Economic Times, April 5 $5^{\text {th }}$, 2013). Though Indians are reported to be less stressed than their western counterparts (Sinha, Willson \& Watson, 2000), the level of depression among Indians are on the rise. Hence, a study on happiness in India at the current situation is warranted.

Few studies have tried to understand the factor structure of $\mathrm{OHI}$, but no study has made use of OHQ. The results of the studies on OHI are not conclusive on the final structure. Hills and Argyle (1998) reported a seven-factor structure with $56.25 \%$ of variance explained on a sample of 275. After a few years, Hills and Argyle (2002) confirmed the seven-factor structure with $60.9 \%$ of variance explained with a sample of 172 subjects. Furnham and Brewin (1990) extracted nine factors with eigenvalues $>1$, but they admit that only three factors with $38.30 \%$ of variance explained were interpretable. Meleddu, Guicciardi, Scalas and Fadda (2012) reported a five-factor structure for the Italian Version of $\mathrm{OHI}$, and they also confirmed the structure with exploratory structural equation modeling in a sample of 782 adolescents. Chiang, Lin and Lee (2016) have reported a three-factor structure for the Chinese Version of OHI, which is referred to as CHI. Liaghatdar, Jafari, Abedi and Samiee (2008) have established the internal reliability, construct and content validity of $\mathrm{OHI}$ among Iranian students. With all these differing results, $\mathrm{OHI}$ is widely used in the American, European and Asian countries as either uni-dimensional (Flynn \& MacLeod, 2015; Medvedev et al., 2017) or with seven or three-factor structure (Meleddu, Guicciardi, Scalas \& Fadda, 2012). Hence, there is the need to understand the underlying factor structure of $\mathrm{OHQ}$ in the Indian context. The present study aims to address this issue using exploratory as well as confirmatory factor analysis techniques.

\section{Study 1}

Study 1 aims to understand the factor structure of OHQ using exploratory factor analysis.

Methods

Sample Size and Participants

There are two main ways of determining the sample size either by roughly estimating the absolute sample size or by using the item ratios. This study has used the latter approach. For exploratory factor analysis, the minimum subject to item ratio suggested is 5:1 (Gorsuch, 1990), 10:1 (Nunnally, 1978), and 20:1 (Hair, Anderson, Tatham \& Black 1998). As opinion is divided, this study has used a ratio of $20: 1$ for better results. Given this ratio, the sample determined is 580. However, Comrey and Lee (1992) have suggested that an absolute sample size 500 is very good whereas a sample of 1000 is excellent as it gives a better frame for analysis as a larger sample enables better precision. Hence 1000 responses were collected. The participants were briefed about the study and then given the OHQ questionnaire. The participants were given enough time to fill in the questionnaire.

1000 Indian university students pursuing their undergraduate education participated in the study. Of these, 130 responses had missing data which were rejected for analysis. Hence, for analysis, only 870 datasets were taken. The mean age of respondents is 21.53 years with a standard deviation of 0.69 . Out of the 870 respondents, 599 were males, and 271 were females.

\section{Questionnaire}

The questionnaire used for this study is the OHQ (Hills and Argyle, 2002) which is a 29item measure on a 6 -point scale (' 1 ' indicates strongly agree and ' 6 ' indicates strongly disagree). The questionnaire was translated into Hindi, the official language of India by four independent translators. For the items where translations were 
different, the translators had a discussion, and the final agreed version was taken. The agreed Hindi version of $\mathrm{OHQ}$ was again back-translated by two independent translators, and then the valid Hindi version of $\mathrm{OHQ}$ was finalized.

Results

\section{Reliability}

The reliability of the questionnaire is checked using chronbach's alpha. The chronbach's alpha is 0.82 , which shows that the internal reliability of the tool for this data set is acceptable.

\section{Exploratory Factor Analysis}

The initial principal component factor analysis has resulted in a six-factor solution with $63.97 \%$ of variance explained. For better interpretation of the factor structure, oblimin rotation is adopted as the factors are related. Table 1 represents the results of the exploratory factor analysis.

\section{Table 1}

Exploratory factor analysis- OHQ

\begin{tabular}{|c|c|c|c|c|c|c|}
\hline Items & $\begin{array}{c}\text { Factor } \\
1\end{array}$ & $\begin{array}{c}\text { Factor } \\
2\end{array}$ & $\begin{array}{c}\text { Factor } \\
3\end{array}$ & $\begin{array}{c}\text { Factor } \\
4\end{array}$ & $\begin{array}{c}\text { Factor } \\
5\end{array}$ & $\begin{array}{c}\text { Factor } \\
6\end{array}$ \\
\hline OHI Q1 & & & & & 0.41 & \\
\hline $\mathrm{OHI} Q 2$ & & & & & & 0.73 \\
\hline $\mathrm{OHI} \mathrm{Q3}$ & & & 0.57 & & & \\
\hline $\mathrm{OHI} \mathrm{Q4}$ & & & & & & 0.48 \\
\hline OHI Q5 & & & & & 0.82 & \\
\hline OHI Q6 & & & & & 0.59 & \\
\hline $\mathrm{OHI} Q 7$ & 0.55 & & & & & \\
\hline OHI Q8 & & & & & & \\
\hline OHI Q9 & & & 0.70 & & & \\
\hline OHI Q10 & & & 0.47 & & & \\
\hline OHI Q11 & & 0.48 & & & & \\
\hline OHI Q12 & & & 0.74 & & & \\
\hline OHI Q13 & & & & 0.49 & & \\
\hline OHI Q14 & & & & 0.79 & & \\
\hline OHI Q15 & & 0.71 & & & & \\
\hline OHI Q16 & & 0.46 & & & & \\
\hline OHI Q17 & & & & & & 0.49 \\
\hline OHI Q18 & 0.58 & & & & & \\
\hline OHI Q19 & & & & 0.53 & & \\
\hline $\mathrm{OHI} Q 20$ & 0.71 & & & & & \\
\hline OHI Q21 & 0.73 & & & & & \\
\hline OHI Q22 & & 0.63 & & & & \\
\hline $\mathrm{OHI} Q 23$ & & & & 0.56 & & \\
\hline OHI Q24 & & & 0.50 & & & \\
\hline OHI Q25 & 0.69 & & & & & \\
\hline OHI Q26 & 0.69 & & & & & \\
\hline OHI Q27 & & & 0.80 & & & \\
\hline OHI Q28 & & & 0.75 & & & \\
\hline $\mathrm{OHI}$ Q29 & & & 0.83 & & & \\
\hline
\end{tabular}

Note. The factor loadings less than 0.4 have been suppressed.
Items with factor loadings above 0.4 are only considered for this study as suggested by Costello and Osborne (2005). Item 8 failed to load with loading greater than 0.4 . The oblimin rotation has resulted in a six-factor structure. The six factors are roughly labeled as life satisfaction, confidence, joy, self-esteem, positive mindset, and Social Interest. Table 2 reports the items falling under each of these factors.

Table 2

Factor Structure-OHQ

\begin{tabular}{llr}
\hline \multicolumn{1}{c}{ Factor } & \multicolumn{1}{c}{ Items } & $\begin{array}{c}\text { Cronbach's } \\
\text { Alpha }\end{array}$ \\
\hline 1. Positive Mindset & $7,18,20,21,25$ & 0.83 \\
2. Joy & $11,15,16,22$ & 0.86 \\
3. Life Satisfaction & $3,9,10,12,24,27,28,29$ & 0.91 \\
4. Confidence & $1,5,6$ & 0.81 \\
5. Self Esteem & $13,14,19,23$ & 0.86 \\
6. Social Interest & $2,4,17,26$ & 0.87 \\
\hline
\end{tabular}

Note.Items are numbered as same as in OHQ

It is unclear whether all these factors converge into the domain of happiness. Hence, a principal component factor analysis is attempted. Such an analysis is useful to extract the uni-dimensional model by restricting the extraction to a single factor. Surprisingly, the single factor could explain only $26.32 \%$ of the variance. Thus, the uni-dimensional model could account for only half the variance explained by the six-factor model.

\section{Study 2}

The factor structure generated using EFA in study 1 is tested using Confirmatory Factor

Analysis (CFA) in study 2. Apart from the six-factor model, the other reported models of $\mathrm{OHI}$ viz seven-factor structure of Hills and Argyle (1998), three-factor structure of Furnham and Brewin (1990) and five-factor-structure of Meleddu et al. (2012) were also tested. The differing models of $\mathrm{OHI}$ were also tested because of several reasons. Firstly, OHQ was devised from OHI with minimal changes like adopting the Likert scale and reversing few items. Secondly, the number of items in OHQ and OHI remains 
the same. Thirdly, OHQ is claimed to be a better version of $\mathrm{OHI}$.

\section{Participants and Procedure}

800 Indian university students pursuing their undergraduate education participated in the study. The mean age of respondents is 21.62 years with a standard deviation of 0.81 . Out of the 800 respondents, 430 were males, and 370 were females. Of the 800 responses, 145 had missing data which were rejected for analysis. Hence, for analyses, only 655 datasets were taken.

\section{Results}

The factor structure extracted from EFA is tested for the fit using Confirmatory Factor Analysis (CFA). CFA allows a researcher to test the relationship between the observed variable and their underlying latent constructs. AMOS 7.0 is used to do CFA. As Maximum likelihood estimation is the default method in AMOS, the pre-requisite for applying the maximum likelihood estimation needs to be checked. Muthen and Kaplan (1992) have suggested that if the variables have skewness and kurtosis ranging from -1 to +1 , then estimating parameters with maximum likelihood method is acceptable. The kurtosis for the 27 items (except item 1 and 8 ) is found to be lying between -0.94 to 0.84 and skewness lying between -0.91 to 0.73 . Hence, maximum likelihood estimation could be applied in estimating the model fit.

CFA is done to analyze the uni-dimensional, six-factor model (as extracted from EFA) and the other reported models of OHI. Table 3 presents the indices for all the tested models. Trucker Lewis Index (TLI) and Comparative Fit Index (CFI) should be higher than 0.90 for accepting a model. As well the Root Mean Squared Error of Approximation (RMSEA) should be less than or equal to 0.05 and the ratio of chi-square to its corresponding degrees of freedom $\left(\chi^{2} / \mathrm{df}\right)$ should be less than or equal to 5 is required $(\mathrm{Hu} \&$ Bentler, 1999).
Table 3

Indices for Tested Models

\begin{tabular}{lllll}
\hline Structure of OHQ & TLI & CFI & RMSEA & x / /df \\
\hline $\begin{array}{l}\text { Uni-Dimensional } \\
\begin{array}{l}\text { Six Factor Model (extracted } \\
\text { by EFA) }\end{array}\end{array}$ & 0.64 & 0.68 & 0.10 & 6.97 \\
$\begin{array}{l}\text { Three Factor Model } \\
\text { (Furnham \& Brewin, 1990) }\end{array}$ & 0.73 & 0.78 & 0.05 & 3.64 \\
$\begin{array}{l}\text { Seven Factor Model (Hills \& } \\
\text { Argyle, 1998) }\end{array}$ & 0.84 & 0.86 & 0.06 & 6.76 \\
$\begin{array}{l}\text { Five Factor Model (Meleddu } \\
\text { et al., 2012) }\end{array}$ & 0.86 & 0.88 & 0.06 & 5.06 \\
\hline
\end{tabular}

The six-factor model yielded fit indices of TLI, (0.91), CFI (0.92), and RMSEA (0.05), falling within the acceptable limits. Hence, the sixfactor model extracted using EFA in study 1 shows a good fit. The uni-dimensional model does not show good fit as the indices of TLI (0.61), CFI (0.68), and RMSEA (0.10) are wider than the acceptable limits. Similarly, the other models tested also do not show good fit.

Both the exploratory and the confirmatory factor analysis could not support the unidimensional model of OHQ. It could be argued that the wider facets that are included in the construction of OHQ have resulted in the nonconvergence of the items into a single domain. As happiness has been looked from the dimensions of negative and positive emotions, well-being, joy and cheerfulness, OHQ has reported a multidimensional model rather than a unidimensional model.

\section{Discussion}

The results of the exploratory factor analysis of OHQ have resulted in a six-factor structure. While tested via CFA, the six-factor model reported a good fit and the uni-dimensional model as proposed by Hills and Argyle (2002) was found to be less fitting than the six-factor model. The findings show that OHQ is a multidimensional scale which in turn agrees with the multidimensional framework of psychological well-being. The six-factor structure of $\mathrm{OHQ}$ is mainly in line with the multi-dimensional structure of OHQ, although it slightly varies from the multi-dimensional models of $\mathrm{OHI}$ as 
proposed by Furnham and Brewin (1990), Hills and Argyle (1998), and Meleddu et al. (2012). Although the six-factor structure of $\mathrm{OHQ}$ includes factors such as self-esteem, confidence, positive mindset and social interest, all these factors can be considered as antecedents of happiness rather than factors of happiness as selfconcepts have reported to be strongly associated with psychological well-being (Thiruchelvi \& Supriya, 2012). Hence, the results of this study strongly support the multi-dimensional approach of well-being and particularly OHQ.

The factor structure of OHQ in India has some common factors and many differences when compared to the Euro-American studies. Meleddu et al. (2012) have reported that items like 'looking attractive', 'feeling mentally alert', 'satisfied with life', 'being happy' are all related. Hills and Argyle (1998) have shown that satisfaction with life comprised of items like 'ability to take anything' and 'decision making'. This study has shown that the items 'feeling that one's life is good', world is a good place to live' and 'having a purpose of life' are related to the memories of past and satisfaction with life. This shows that life satisfaction in India is not being judged based on the present conditions alone as in Western culture, but by evaluating the past experiences of life too. It is a unique characteristic of India.

This study reports that feeling healthier is related to satisfaction with life. This result is in congruence with the results of Gerdtham and Johannesson (2001). Items namely 'laugh a lot', 'finding beauty in something', 'experience joy and elation' are grouped in this study. The study by Furnham and Brewin (1990) reported items namely 'taking a decision', 'experience joy', 'having control of life' in one group. Hence, people experience joy at individual levels in the Euro-American culture, which is a characteristic of an individualistic culture. In India, selfrelated concepts like 'controlling life', and 'taking decisions' are grouped, and it is not related to joy.

Meleddu et al. (2012) found items namely 'laugh a lot', 'ability to take anything', 'having great energy' falling in the same group of self-fulfillments whereas these study results are different. Westerners practice self-maintenance strategy like self-enhancement which is not found in Asians (Lu \& Gilmour, 2004), especially Indians. Joy and self-concept are two different factors in the Indian context. Self-esteem is more related to satisfaction with life in Hill and Argyle's (1998) study. Hence, self-concept is more related to satisfaction with life in the Euro-American culture. This is not the case in Indian culture. Similar results were reported by Diener and Diener (2009), and Moksnes and Espnes (2013). Bhagavad Gita, the holy book for Hinduism, the major religion of India insists on doing the duty without expecting the results. Hence, satisfaction with life is not related to being confident of doing one's duty or having high self- esteem.

Feeling a sense of purpose of life and mentally alert and having great energy are related to selfconcepts. Hence, a person's self-concept is more related to cognition and action-oriented in the West, which is called an independent self or Euro-American self-ways (Markus \& Kitayama, 1998). Indians view self as being bound to others, which is called as interdependent self or Asian Self-Ways (Markus \& Kitayama, 1998). The item 'pleased with the way I am' is a component of satisfaction with life in Meleddu et al.'s (2012) study, but it is part of confidence in this study. In the West, life satisfaction is related to enthusiasm, but in India, life satisfaction is related to emotions like peace and harmony.

A striking difference noted in this study is that the item 'having a good influence over events' is related to a positive outlook in the West (Hills \& Argyle, 1998), but it is related to sociability in India. Indians do not look an event as a sequence of actions, but they consider it as a sequence of people involved processes. This is a critical difference as India is a collectivist country and the West is characterized by individualism. Happiness in India is always a collective concept (Nagar, 2017).

Hence, OHQ is a combination of many psychological characteristics. Any model of happiness could not explain many of these factors, for example, self-esteem and self-efficacy. It has already been reported that the item 
content of $\mathrm{OHQ}$ failed to differentiate subjective well-being from its antecedents and precedents (Kashdan, 2004). The potential development of a revised OHQ is possible as OHQ is a widely used measure and is also available in the public domain.

Even though reliabilities are satisfactory for all the six factors, the number of negative items in the tool is quite lesser when compared to the positive items. This unequal ratio of positive and negative items hints at the psychometrically unsatisfactory nature of the tool. Hence, reversal of some of the items should be generated, and further factor structure can be analyzed. Though the six factors generated could be explainable, the existence of the superordinate general factor 'happiness' should be looked into. Hence, a hierarchical model can be tested.

The study has not attempted to establish the existence of the happiness domain. It is advised for the researchers to explore the factor structure of the tool and use it for further analysis. A valid measurement tool with well-structured subscales is of great help in research to understand the concept in a better way. Since happiness is an abstract construct, it has to be handled with utmost care while measuring the construct and its sub components. Until the subcomponents and the construct are generalized with repetitive studies, work on the area of happiness with $\mathrm{OHQ}$ will remain vague. The validation of $\mathrm{OHQ}$ across different samples is still open.

\section{References}

Ahuvia, A. C. (2002). Individualism/collectivism and cultures of happiness: A theoretical conjecture on the relationship between consumption, culture and subjective wellbeing at the national level. Journal of Happiness Studies, 3(1), 23-36. https://doi.o $\mathrm{rg} / 10.1023 / \mathrm{A}: 1015682121103$

Argyle, M. (2001). The psychology of happiness. East Sussex: Routledge.

Argyle, M., Martin, M., \& Crossland, J. (1989). Happiness as a Function of Personality and Social Encounters. In J. P. Forgas and J.
M. Innes (Ed.), Recent advances in social psychology: An international perspective (pp. 189-203). North-Holland: Elsevier Science Publishers.

Beck, A. T., Ward, C. H., Mendelson, M., Mock, J., \& Erbaugh, J. (1961). An inventory for measuring. Archives of General Psychiatry, 4(6), 561-571. https://doi.org/10.1001/arch psyc. 1961.01710120031004

Biswas-Diener, R., Tay, L., \& Diener, E. (2012). Happiness in India. In H. Selin \& G. Davey (Eds.), Happiness across cultures (pp. 13-25). Springer, Dordrecht.https://doi.org/10.100 7/978-94-007-2700-7 2

Chamorro-Premuzic, T., Bennett, E., \& Furnham, A. (2007). The happy personality: Mediational role of trait emotional intelligence. Personality and Individual Differences, 42(8), 1633-1639. ht tps://doi.org/10.1016/j.paid.2006.10.029

Chakraborty, B., Maji, S., Sen, A., Mallik, I., Baidya, S., \& Dwibedi, E. (2018). A study on happiness and related factors among Indian college students. Journal of Quantitative Economics, 1-22. https://doi.or $\mathrm{g} / 10.1007 / \mathrm{s} 40953-018-0125-8$

Chiang, H. H., Lin, L., \& Lee, T. S. H. (2016). Psychometric integrity of the Chinese Happiness Inventory among retired older people in Taiwan. Geriatrics $\mathbb{E}$ Gerontology International, 16(7), 865-872. https://doi.or g/10.1111/ggi.12568

Church, A. T. (2000). Culture and personality: Toward an integrated cultural trait psychology. Journal of Personality, 68(4), 651-703. https://doi.org/10.1111/1467-649 4.00112

Comrey, A. L., \& Lee, H. B. (1992). A first course in factor analysis. New York, NY: Psychology Press.

Costello, A. B., \& Osborne, J. W. (2005). Best practices in exploratory factor analysis: Four recommendations for getting the most from your analysis. Practical Assessment, Research $\mathcal{E}$ Evaluation, 10(7), 1-9. https://w ww.pareonline.net/pdf/v10n7.pdf

Diener, E. (2000). Subjective well-being: The science of happiness and a proposal for 
a national index. American Psychologist, 55(1), 34-43.

Diener, E., \& Diener, M. (2009). Cross-cultural correlates of life satisfaction and self-esteem. In Culture and Well-Being (pp. 71-91). https:// doi.org/10.1007/978-90-481-2352-0_4

Diener, E., Oishi, S., \& Ryan, K. L. (2013). Universals and cultural differences in the causes and structure of happiness: A multilevel review. In C. L. M. Keyes (Ed.), Mental well-being (pp. 153-176). Netherlands: Springer. https://doi.org/10.1 007/978-94-007-5195-8 8

Diener, E., Suh, E. M., Lucas, R. E., \& Smith, H. L. (1999). Subjective well-being: Three decades of progress. Psychological Bulletin, 125(2), 276- 302.

Diener, E., Tay, L., \& Oishi, S. (2013). Rising income and the subjective well-being of nations. Journal of Personality and Social Psychology, 104(2), 267-276.

Flynn, D. M., \& MacLeod, S. (2015). Determinants of happiness in undergraduate university students. College Student Journal, 49(3), 452-460. https://doi. org/10.1037/a0030487

Furnham, A., \& Brewin, C. R. (1990). Personality and happiness. Personality and Individual Differences, 11(10), 1093-1096. https:// doi.org/10.1016/0191-8869(90)90138-H

Gerdtham, U. G., \& Johannesson, M. (2001). The relationship between happiness, health, and socio-economic factors: Results based on Swedish microdata. The Journal of Socio-Economics, 30 (6), 553-557. https://do i.org/10.1016/S1053-5357(01)00118-4

Gorsuch, R. L. (1990). Common factor analysis versus component analysis: Some well- and little-known facts. Multivariate Behavioral Research, 25(1), 33-39. https://doi.org/10.1 207/s15327906mbr2501_3

Hair, J. F., Anderson, R. E., Tatham, R. L., \& Black, W. C. (1998). Multivariate data analysis. New York, NY: Prentice Hall International.
Hills, P., \& Argyle, M. (1998). Positive moods derived from leisure and their relationship to happiness and personality. Personality and Individual Differences, 25 (3), 523-535. https://doi.org/10.1016/S0191-88 69(98)00082-8

Hills, P., \& Argyle, M. (2002). The Oxford Happiness Questionnaire: a compact scale for the measurement of psychological wellbeing. Personality and Individual Differences, 33(7), 1073- 1082. https://doi.org/10.1016 /S0191-8869(01)00213-6

Holder, M. D. (2012). Understanding the construct of positive well-being and happiness. In Happiness in Children (pp. 14). Netherlands: Springer. https://doi.org/1 0.1007/978-94-007-4414-1_1

Howell, R. T., Chong, W. T., Howell, C. J., \& Schwabe, K. (2012). Happiness and life satisfaction in Malaysia. In H. Selin \& G. Davey (Eds.), Happiness Across Cultures (pp. 43-55). Netherlands: Springer. https:/ /doi.org/10.1007/978-94-007-2700-7_4

Hu, L., \& Bentler, P. M. (1999). Cutoff criteria for fit indexes in covariance structure analysis: Conventional criteria versus new alternatives. Structural Equation Modeling: A Multidisciplinary Journal, 6(1), 1-55. http s://doi.org/10.1080/10705519909540118

Islam, G. (2012). Happiness in Brazil. In H. Selin \& G. Davey (Eds.), Happiness Across Cultures, (Vol. 6, pp. 227-240). Netherlands: Springer. https://doi.org/10.1 007/978-94-007-2700-7_16

Kashdan, T. B. (2004). The assessment of subjective well-being (issues raised by the Oxford Happiness Questionnaire). Personality and Individual Differences, 36(5), 1225-1232. https://doi.org/10.1016/S01918869(03)00213-7

Kitayama, S., Markus, H. R., \& Kurokawa, M. (2000). Culture, emotion, and well-being: Good feelings in Japan and the United States. Cognition E Emotion, 14(1), 93-124. https://doi.org/10.1080/026999300379003

Liaghatdar, M. J., Jafari, E., Abedi, M. R., \& Samiee, F. (2008). Reliability and Validity of the Oxford Happiness Inventory among 
University Students in Iran. The Spanish Journal of Psychology, 11 (1), 310-313. https ://doi.org/10.1017/S1138741600004340

Lu, L., \& Gilmour, R. (2004). Culture and conceptions of happiness: Individual oriented and social oriented SWB. Journal of Happiness Studies, 5(3), 269-291. https:// doi.org/10.1007/s10902-004-8789-5

Lu, L., Gilmour, R., \& Kao, S. F. (2001). Cultural values and happiness: An EastWest dialogue. The Journal of Social Psychology, 141(4), 477-493. https://doi.org /10.1080/00224540109600566

Lu, L., \& Shih, J. B. (1997). Personality and happiness: Is mental health a mediator? Personality and Individual Differences, 22 (2), 249-256.

Markus, H. R., \& Kitayama, S. (1998). The cultural psychology of personality. Journal of Cross-Cultural Psychology, 29(1), 63-87. htt ps://doi.org/10.1177/0022022198291004

Medvedev, O. N., Siegert, R. J., Mohamed, A. D., Shepherd, D., Landhuis, E., \& Krägeloh, C. U. (2017). The Oxford Happiness Questionnaire: Transformation from an ordinal to an interval measure using rasch analysis. Journal of Happiness Studies, 18(5), 1425-1443. https://doi.org/10.1007/s10902 $-016-9784-3$

Meleddu, M., Guicciardi, M., Scalas, L. F., \& Fadda, D. (2012). Validation of an Italian Version of the Oxford Happiness Inventory in Adolescence. Journal of Personality Assessment, 94(2), 175-185. https://doi.org /10.1080/00223891.2011.645931

Moksnes, U. K., \& Espnes, G. A. (2013). Self-esteem and life satisfaction in adolescents—-gender and age as potential moderators. Quality of Life Research, 22 (10), 2921-2928. https://doi.org/10.1007/s11136 $-013-0427-4$

Muthen, B., \& Kaplan, D. (1992). A comparison of some methodologies for the factor analysis of non-normal Likert variables: A note on the size of the model. British Journal of Mathematical and Statistical Psychology, 45(1), 19-30. https://doi.org/10.1111/j.204 4-8317.1992.tb00975.x
Nagar, I. (2017). Self-Regulation for sustaining happiness and well-being: An Indian perspective. Psychological Studies, 1-6. https ://doi.org/10.1007/s12646-017-0403-0

Nunnally, J. C. (1978). Psychometric theory. New York: McGraw Hill.

Oishi, S., Diener, E. F., Lucas, R. E., \& Suh, E. M. (1999). Cross-Cultural variations in predictors of life satisfaction: perspectives from needs and values. Personality and Social Psychology Bulletin, 25(8), 980-990. https:// doi.org/10.1177/01461672992511006

Oishi, S., \& Gilbert, E. A. (2016). Current and future directions in culture and happiness research. Current Opinion in Psychology, 8, 54-58. https://doi.org/10.1016/j.copsyc.201 5.10 .005

Pavot, W. (2018). The cornerstone of research on subjective well-being: Valid assessment methodology. In E. Diener, S. Oishi, \& L. Tay (Eds.), Handbook of well-being (pp. 1-11). Salt Lake City, UT: DEF Publishers. Retroeved from https://www.nobascholar.c om/chapters/15/download.pdf

Russell, J. A., \& Barrett, L. F. (1999). Core affect, prototypical emotional episodes, and other things called emotion: Dissecting the elephant. Journal of Personality and Social Psychology, 76(5), 805-819.

Saddichha, S. (2010). Diagnosis and treatment of chronic insomnia. Annals of Indian Academy of Neurology, 13(2), 94-102. https://doi.org/ 10.4103/0972-2327.64628

Sinha, B. K., Willson, L. R., \& Watson, D. C. (2000). Stress and coping among students in India and Canada. Canadian Journal of Behavioural Science/Revue canadienne des sciences $d u$ comportement, 32(4), 218.

Slocum-Gori, S. L., Zumbo, B. D., Michalos, A. C., \& Diener, E. (2009). A note on the dimensionality of Quality of Life Scales: An illustration with the Satisfaction with Life Scale (SWLS). Social Indicators Research, 92 (3), 489-496. https://doi.org/10.1007/s11 205-008-9303-y

Thiruchelvi, A., \& Supriya, M. V. (2012). An investigation on the mediating role of coping strategies on locus of control-well- 
being relationship. The Spanish Journal of Psychology, 15(1), 156-165.

Uchida, Y., \& Ogihara, Y. (2012). Personal or interpersonal construal of happiness: A cultural psychological perspective. International Journal of Wellbeing, 2(4), 354-369.

Vaingankar, J. A., Subramaiam, M., Lim, Y. W., Sherbourne, C., Luo, N., Ryan, G., ... \& Chong, S. A. (2012). From well-being to positive mental health: conceptualization and qualitative development of an instrument in Singapore. Quality of Life Research, 21(10), 1785-1794. https://doi.or g/10.1007/s11136-011-0105-3

Veenhoven, R. (1991). Is happiness relative? Social Indicators Research, 24(1), 1-34. http s://doi.org/10.1007/BF00292648

Veenhoven, R. (2010). Greater happiness for a greater number. Journal of happiness studies, 11(5), 605-629. https://doi.org/10.1007/s10 902-010-9204-z

Wang, F., \& Wang, D. (2016). Place, geographical context and subjective well-being: State of art and future directions. In D. Wang \& S. He (Eds.), Mobility, Sociability and Wellbeing of Urban Living (pp.189-230). Berlin Heidelberg: Springer. https://doi.org/10.100 7/978-3-662-48184-4

\section{Notes}

* Research article. 